Gerión. Revista de Historia Antigua

ISSN: 0213-0181

\title{
Aríste politeía: el ordenamiento constitucional espartano en la tradición griega clásica y helenística
}

\author{
César Fornis Vaquero ${ }^{1}$
}

Recibido: 31 de marzo de 2019 / Aceptado: 14 de junio de 2019

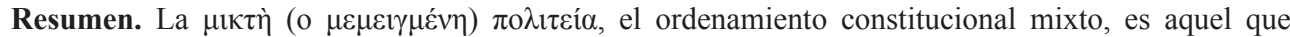
combina de manera sabia y proporcionada elementos de los regímenes políticos puros o simples (monarquía, aristocracia y democracia) como garantía de estabilidad y de paz interna. Esparta, que siempre sedujo a los constructores de ciudades ideales, será el primer ejemplo de una larga lista de estados en la historia del pensamiento occidental de esta suerte de ápí $\tau \tau \eta \pi$ o $\imath \tau \varepsilon i ́ \alpha$, de "Constitución" óptima, atemperada, modélica, pero al mismo tiempo ilusoria. En el presente trabajo examinaremos el destacado papel que juega Esparta en la génesis y el desarrollo de esta teoría política en la tradición griega clásica y helenística.

Palabras clave: Esparta; constitución mixta; politeía; teoría política; Licurgo; monarquía; aristocracia; democracia.

\section{[en] Ariste politeia: The Spartan Constitution in the Classical and Hellenistic Greek Tradition}

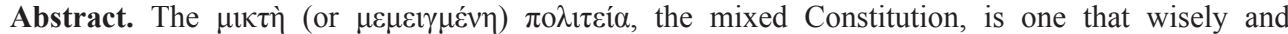
proportionally combines elements of pure or simple political regimes (monarchy, aristocracy and democracy) as a guarantee of stability and internal peace. Sparta, who always seduced the ideal city builders, will be the first example in a long list of states in the history of Western thought of this sort of

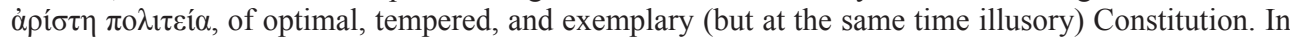
the present work we will examine the outstanding role that Sparta plays in the genesis and development of this political theory in the Classical and Hellenistic Greek tradition.
\end{abstract}

Keywords: Sparta; Mixed Constitution; Politeia; Political Theory; Lykourgos; Monarchy; Aristocracy; Democracy.

Sumario. 1. Introducción. 2. Platón. 3. Aristóteles. 4. Tratados sobre politeía y epitedeúmata lacedemonios. 5. Isócrates. 6. Historiografía "retórica". 7. Polibio. 8. Cicerón y el final de la reflexión teórica sobre la Constitución mixta. 9. Referencias bibliográficas.

Cómo citar: Fornis, C. (2019): Aríste politeía: el ordenamiento constitucional espartano en la tradición griega clásica y helenística, en Gerión 37/2, 323-341.

1 Universidad de Sevilla.

E-mail: cfornis@us.es 


\section{Introducción ${ }^{2}$}

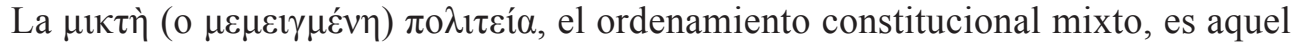
que combina de manera sabia y proporcionada elementos de los regímenes políticos puros o simples (monarquía, aristocracia y democracia) como garantía de estabilidad y de paz interna. Esparta, que siempre sedujo a los constructores de ciudades ideales, será el primer ejemplo de una larga lista de estados en la historia

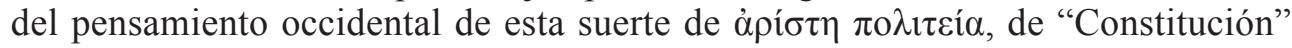
óptima. Se trata, sin embargo, de una quimera, un constructo que ha servido para proyectar la imagen de un perfecto y armónico equilibrio de poderes, cuando en realidad la balanza se inclinaba conspicuamente a favor de uno (generalmente la oligarquía). En el presente trabajo examinaremos el destacado papel que juega Esparta en la génesis y el desarrollo de esta teoría política en la tradición griega clásica y helenística.

Después de que los griegos iniciaran en la segunda mitad del siglo $\mathrm{V}$ el estudio de las diferentes politeíai y el debate sobre cuál de ellas era la mejor, encontramos ya a comienzos del siguiente prefigurada en Platón la teoría de la miktè politeía. ${ }^{3}$ Jenofonte, su compañero en unos círculos socráticos donde la impronta espartana es poderosa ${ }^{4}$ se adelantó en la redacción de una Constitución de los lacedemonios en la que expresaba su entusiasmo por unas leyes, instituciones (políticas y sociales) y costumbres que se atribuían en su mayoría a Licurgo, legislador mítico instalado en la acronía ${ }^{5}$ que había llevado la eudaimonía a la ciudad, ${ }^{6}$ "obligando a todos a practicar públicamente todas las virtudes", ${ }^{7}$ hasta hacer de Esparta "el único lugar donde la excelencia moral es un deber público", ${ }^{8}$ en una especie de kalokagathía aristodemocrática. ${ }^{9}$ Pero el historiador ateniense, que declara sentirse sorprendido (y decepcionado) de que nadie se decida a imitar unos epitedeúmata que todos alaban, ${ }^{10}$ no intentó definir ni clasificar su régimen político, mucho menos teorizar sobre su naturaleza; puso el énfasis en la realeza, "la única institución que se conserva exactamente igual a como se creó en un principio", ${ }^{11}$ es decir, la única que no ha sufrido los cambios y la degradación que han dado al traste con el kósmos licurgueo en su propio tiempo, como se lamenta en el famoso capítulo 14, opinión a la que sin duda no es ajena la relación clientelar que mantenía con el rey euripóntida Agesilao II. ${ }^{12}$

\footnotetext{
El presente trabajo se ha elaborado en el seno del proyecto de investigación HAR2015-63549-P.

El juicio de Tucídides sobre el ordenamiento de los Cinco Mil en la Atenas de 411, "un mesurado equilibrio entre los oligarcas y la masa" (8.97.2; trad. Torres Esbarranch, BCG, 1992), es antes una calificación de moderación de la oligarquía que una alusión a un ordenamiento constitucional mixto.

$4 \quad$ Plácido 1991.

Véase Paradiso 2000.

X. Lac. 1.2 .

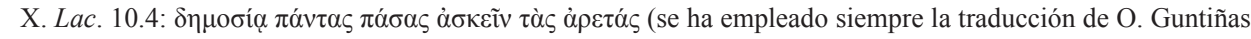
Tuñón, BCG, Madrid, 1984).

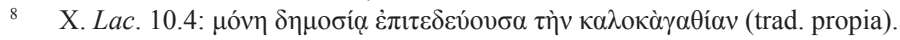

9 Sobre la contribución decisiva de Jenofonte a la mitografía de Licurgo, David 2007. Con Jenofonte, "Esparta se baña en la kalokagathía", en expresión de Richer 2007, 409.

10 X. Lac. 10.8 .

11 X. Lac. 15.1

12 Un reciente estado de la cuestión, actualizado bibliográficamente, sobre la representación de Esparta y de los espartanos en Jenofonte, en Christesen 2017.
} 


\section{Platón}

Fue Platón quien elevó a Esparta a la categoría de modelo y utopía política. ${ }^{13}$ En su sociedad y en sus instituciones se inspiró, como ya reconociera Plutarco, para la construcción teórica de sus ciudades ideales de Calípolis, en la República, y Magnesia, en las Leyes. ${ }^{14}$ En estas "ensoñaciones sociales" del fundador de la Academia encontramos señas de identidad espartanas como el respeto a la autoridad (con un lugar privilegiado para los ancianos, por lo que se ha hablado de gerontocracia) y a las Leyes (con mayúscula, pues son inamovibles e incuestionables), la compulsión del matrimonio y el control de los nacimientos, la educación pública y obligatoria, incluyendo la femenina (fomentando el ejercicio físico y los cantos y danzas corales), las comidas comunitarias (también extendidas a las mujeres), el minoritario y selecto cuerpo cívico, que lleva un estilo de vida sencillo y se abstiene tanto de actividades comerciales y artesanales (con la consiguiente contracción de las mismas y la tendencia a la autarquía) como del contacto con extranjeros. Ahora bien, no todo lo lacedemonio es del agrado de Platón, que censura la vida desordenada y disipada de sus mujeres, cuya relajación de costumbres figura en el debe del legislador Licurgo, y la excesiva belicosidad de los varones, que tienen "la politeía de un campamento militar ( $\sigma \tau \rho \alpha \tau o \pi \varepsilon ́ \delta o v)$, impropia de los que viven en ciudades". ${ }^{15}$ Platón no es sino el exponente más conspicuo de un fenómeno más generalizado que hizo de Esparta el objeto de atención preferencial de los constructores de ciudades ideales, siempre reacios, cuando no decididamente hostiles, tanto al régimen como al modo de vida democráticos. ${ }^{16}$ Porque, pregunta Diotima en el Banquete, "¿quién no preferiría, en lugar de engendrar hijos de su propia sangre, dejar tras de sí los que Licurgo dejó en Lacedemonia [sus leyes], salvadoras de Lacedemonia y, podemos incluso decir, de toda Grecia". ${ }^{17}$

En el libro VIII de la República, Esparta, como Creta, es clasificada como una timarquía (o timocracia), ${ }^{18}$ término que inventa Platón para designar un régimen basado en el honor (timé) que, siendo imperfecto, es el mejor entre los imperfectos, ${ }^{19}$ con lo que alberga cualidades admirables que le aproximan a su Estado ideal (respeto

13 En su influyente obra La sociedad abierta y sus enemigos (2006 [1945], 54-55), Karl Popper llegó a decir que "Merced a esta doctrina de la similitud entre Esparta y el Estado perfecto, Platón se convirtió en uno de los mayores propagandistas de lo que cabría denominar "el gran mito de Esparta". Para Esparta en el pensamiento platónico: Ollier 1933, 217-293; Keber 1957; Morrow 1960, 40-73; Tigerstedt 1965, 244-280; Rawson 1969, 61-72; Lévy 2005. De Brasi 2013 es un estudio monográfico de corte revisionista según el cual, dentro de una función esencialmente retórica y argumentativa, los diálogos platónicos no muestran una opinión unívoca favorable -incluso en ocasiones podría ser bastante crítica- de la polis lacedemonia. Se centran en las Leyes: Powell 1994; Hodkinson 2005, 227-237, 251-252; Ducat 2016. Y en la República: Herrmann 2018; Humble 2018 (comparando este diálogo con la Constitución de los lacedemonios jenofóntica).

14 Plu. Lyk. 31.2.

15 Pl. Lg. 637c, 666e, 806c (mientras no se indique lo contrario, ofrecemos aquí la trad. F. Lisi, BCG, 1999). Véase especialmente Tigerstedt 1965, 254-276, quien no obstante constata también las diferencias e incluso se resiste a ver en Esparta un nítido referente de las utopías platónicas. A contrario, Cartledge 1999, 328, va mucho más allá de Platón en su afirmación de que Esparta "por la vía del mirage, fue fons et origo de la totalidad de la utopiografía política de la tradición occidental" (trad. propia). Para Futter 2012, la República platónica puede verse como una extensión e idealización de las medidas socioeconómicas espartanas, pero presenta en cambio unas estructuras formales de gobierno irreconciliables con la polis lacedemonia.

16 Ollier 1933, 207.

17 Pl. Smp. 209d.

18 Pl. R. 544c.

19 Pl. R. 544a. 
a los gobernantes, liberación de la clase guerrera de las tareas banáusicas, comidas comunitarias, prácticas gimnásticas y militares),${ }^{20} \mathrm{si}$ bien no es menos cierto que se ve amenazado por el creciente individualismo, el afán de riqueza y un militarismo exacerbado. ${ }^{21}$ Sin embargo, en el libro IV de las Leyes, el espartiata Megilo no se ve capaz de definir la politeía de su polis, porque por un lado el poder de los éforos reviste una forma tiránica, otras veces parece la más democrática de las ciudades, pero tampoco se le puede negar su carácter aristocrático ni que tiene una realeza vitalicia y antiquísima. $^{22}$

En el libro anterior, el III, se afirma que los lacedemonios, y también los cretenses, son los mejor gobernados - persas y atenienses lo fueron en el pasado, pero se malograron porque abusaron del principio monárquico los primeros y de la libertad

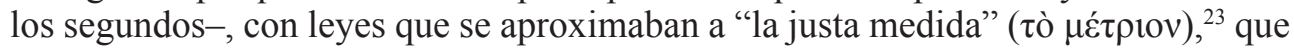
no dan "a pobre o rico, particular o rey ningún tipo de honor o educación distinguida que no os hubiera revelado a instancias de un dios aquel ser divino que actuó entre vosotros al comienzo" 24 y preservan "una cierta igualdad de bienes" (iَó $\tau \tau \tau \alpha \tau \tilde{\eta} \varsigma$ ov̉ $\mathbf{i}_{\alpha \varsigma}$ ), pues "las tierras fueron repartidas sin disputas y no hay deudas de importancia ni antiguas". ${ }^{25}$ Cabe recordar en este punto que las no pocas similitudes que Esparta comparte con Creta en el espectro sociopolítico, con "leyes que son como hermanas

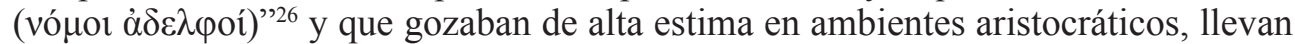
a Platón a sumarse a la tradición que, como mínimo desde las Kretiká de Carón de Lámpsaco, ${ }^{27}$ hacía a Licurgo viajar hasta dicha isla, fuente de derecho desde los míticos reyes Radamantis y Minos, para inspirarse a la hora de dar a luz una legislación que habría eludido la temible stásis: ${ }^{28}$ en puridad, tal Constitución cretense nunca existió, es una invención que trataba de homogeneizar los sistemas políticos de las aproximadamente cincuenta póleis de la isla. ${ }^{29}$ Como es conocido, una segunda tradición proclamaba empero que Licurgo había recibido la Gran Retra en Delfos, directamente de la Pitia, portavoz del dios Apolo. ${ }^{30}$ Éforo resolvería la discrepancia, con notable éxito, convirtiendo al oráculo en sancionador de unas leyes licurgueas de inspiración cretense pero mejoradas, llevadas a la perfección. ${ }^{31}$

En el pensamiento platónico, como en el jenofóntico, la realeza es el poder prístino del ordenamiento lacedemonio, ${ }^{32}$ unos reyes cuyo linaje, tan preclaro y selecto que a

$20 \quad$ Pl. R. 547d.

21 Pl. $R$. 547e-548b. El timocrático sería un régimen intermedio entre el régimen perfecto, el aristocrático, y su deformación, el oligárquico, participando de ambos; Lévy 2005, 221-224 para una mayor profundización.

22 P1. $L g .712$ d-e.

23 P1. Lg. 693d-694a.

24 Pl. Lg. 696a.

25 Pl. Lg. 684d-e (trad. propia).

26 P1. Lg. 683a. Cf. 625a, 634d-e, 636b-d, 641e, 660b-d, 666d, 673b-674a, 780b, 836b, 842b.

$27 \quad$ FGH $262 \mathrm{~T} 1$.

28 Hdt. 1.65.4, que afirma que esto es lo sostenido por los propios espartanos; Plb. 6.45.2; Paus. 3.2.4; Plu. Lyk. 4.1; Ps.Pl. Mor. 318c-d, 320b; Arist. frg. 535 Rose y Pol. 1271b20-1272a12; Ephor. FGH 70 F149.17-19 apud Str.

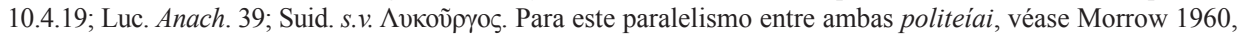
32-39 y, más recientemente, Cuniberti 2000.

29 Véase Perlman 2005.

30 Tyrt. frg. 3 Diehl = D.S. 7.12.6; Hdt. 1.65.2; Plu. Lyk. 6.1-2, 10.

31 Ephor. FGH 70 F149.17-19 apud Str. 10.4.19 (cf. 10.4.16). Sobre la primacía de la legislación cretense o de la lacedemonia, véase Nafissi 1983-84.

32 Ducat 2016 y 2017, 253, que habla de "pivote del régimen". Morrow 1960, 525-526 ya aclaró que, cuando Platón habla de monarquía como elemento constitutivo de un Estado, no se trata tanto de $\beta \alpha \sigma i \lambda \varepsilon i ́ \alpha$ stricto sensu

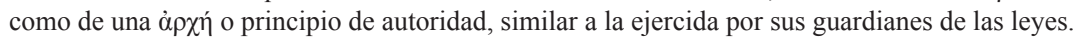


través de Heracles y Agamenón llega hasta el mismo Zeus, es exaltado en el pseudoplatónico Alcibiades I a fin de rebajar las ambiciosas expectativas del joven y orgulloso Alcibíades. ${ }^{33}$ Fue el dios que cuida de los lacedemonios (Apolo) quien la hizo "más mesurada" al implantar la diarquía, basada en un linaje geminado a partir de una única estirpe, con lo que se evitó que la monarquía deviniera absoluta; más

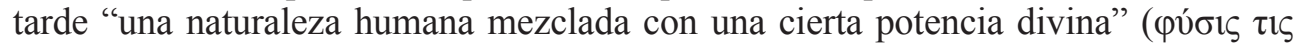

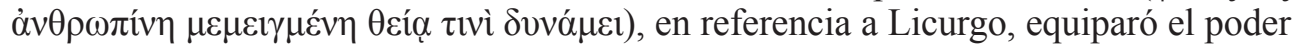
de los reyes con el de los veintiocho ancianos de la Gerousía, encarnación de la

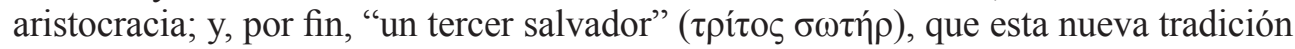
del siglo IV a la que se sumará también Aristóteles -y la Lakedaimoniôn Politeía producida por su escuela- personifica en el rey Teopompo, ${ }^{34}$ frenó aún más "la insolencia y la violencia" de la autoridad real con la creación de la eforía, "aproximándola así al gobierno elegido por sorteo" (a la democracia, por más que esta arché fuera en realidad electiva). El interlocutor ateniense de Megilo cierra su argumentación con el aserto de que, al mezclarse con los elementos necesarios, la monarquía "mantuvo la mesura, se salvó a sí misma y se convirtió en causa de salvación para el resto [de los griegos]". ${ }^{35}$ Para Platón, "el Estado debe estar bien mezclado, como una cratera de vino". ${ }^{36}$ Aunque en ninguna parte de las obras

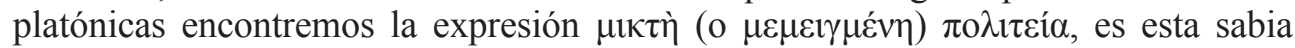

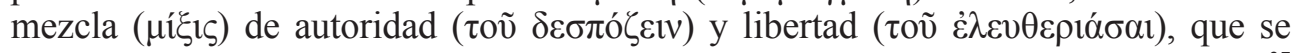
corresponden con las dos formas madres de gobierno, la monárquica y la democrática, ${ }^{37}$ la garante de la perennidad, la estabilidad y el buen gobierno de los lacedemonios, frente a las otras dos monarquías dorias originales, la argiva y la mesenia, que se

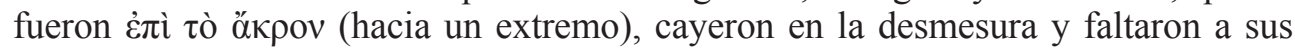
juramentos y a sus leyes..$^{38}$ Pero es también el producto de un desarrollo paulatino, en diferentes fases y en función de las necesidades, y no por entero la obra de un Licurgo transmutado en demiurgo creador, como en Jenofonte, ${ }^{39}$ sin dejar de ser por ello una genuina politeía; es más, son las demás formas de gobierno las que no pasan de ser "Estados-facción en los que los ciudadanos son dominados y esclavizados por una parte de ellos mismos y cada uno recibe el nombre a partir del elemento gobernante". ${ }^{40}$

\section{Aristóteles}

Con Aristóteles, Esparta pierde la preeminencia que había tenido en la escuela socrática, se convierte en un elemento más, si bien importante, en el análisis de los

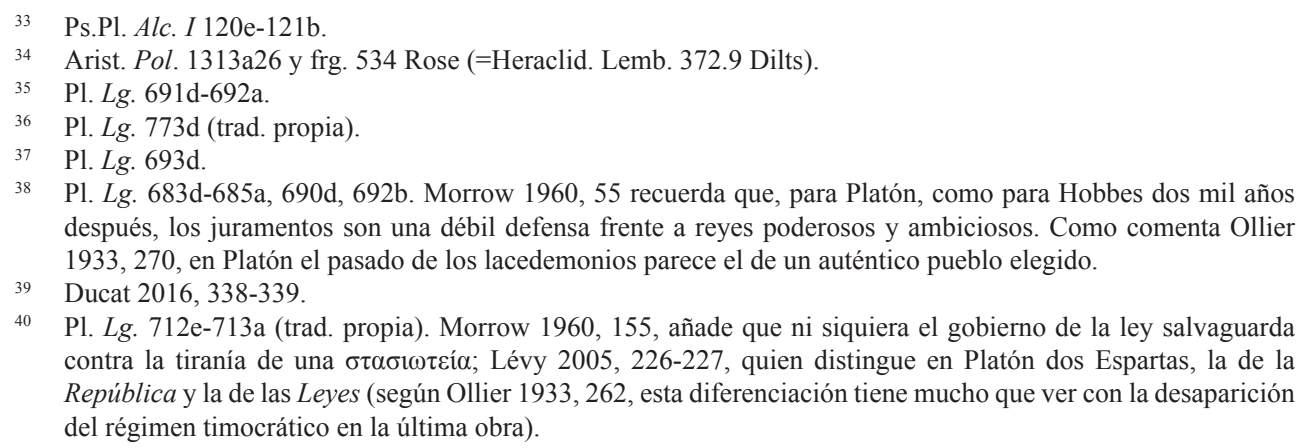
después, los juramentos son una débil defensa frente a reyes poderosos y ambiciosos. Como comenta Ollier 1933, 270, en Platón el pasado de los lacedemonios parece el de un auténtico pueblo elegido.

39 Ducat 2016, 338-339.

40 Pl. $L g .712 \mathrm{e}-713$ a (trad. propia). Morrow 1960, 155, añade que ni siquiera el gobierno de la ley salvaguarda contra la tiranía de una $\sigma \tau \alpha \sigma i \omega \tau \varepsilon i ́ \alpha$; Lévy 2005, 226-227, quien distingue en Platón dos Espartas, la de la República y la de las Leyes (según Ollier 1933, 262, esta diferenciación tiene mucho que ver con la desaparición del régimen timocrático en la última obra). 
modelos constitucionales helenos. ${ }^{41}$ En el Estagirita prima más la taxonomía que el idealismo, más la pretensión de clasificar y analizar el régimen espartano que la de convertirlo en modelo ideal. Y no deja de aludir a la situación contemporánea, a diferencia de un Platón que siempre habla de la Esparta del pasado. ${ }^{42}$

En consonancia, en la Política aristotélica la admiración por Esparta mostrada por su maestro se difumina y el análisis se torna mucho más aquilatado. En el libro IV todavía es posible leer pasajes de aprobación hacia Licurgo - un ciudadano

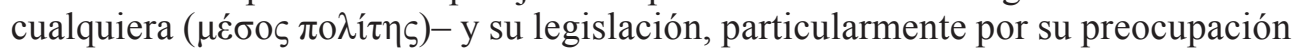
por la educación comunitaria, que no distingue entre ricos y pobres, y por no hacer ostensibles públicamente las diferencias socioeconómicas entre el cuerpo cívico, ${ }^{43}$ lo que no impide que en el libro VII se describa a este "Jano" como un legislador poco afortunado en la medida en que sus leyes portan en sí mismas el germen de la decadencia y de la corrupción. ${ }^{44}$ Pero es en un largo pasaje del libro II donde Aristóteles despliega una profunda y ácida crítica a las instituciones lacedemonias: a los syssítia, que excluyen de la ciudadanía si no se hacen las debidas aportaciones y así la debilitan en lugar de fortalecerla; al poder de los éforos -elegidos de entre

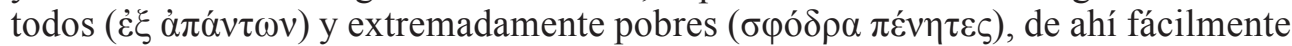
venales-, que se asemeja al de los tiranos (iøotúpavvov) y hace que los reyes mismos les cortejen; a los gérontes, cuyo proceso de selección es demasiado "pueril" y alienta a los individuos ambiciosos, que disfrutan del cargo de por vida (cuando "hay, como la del cuerpo, también una vejez de la mente"), no rinden cuentas de sus actos y toman las decisiones según su criterio y no según la ley; a la licenciosidad, el gusto por el lujo y la molicie de las mujeres, que considera han alcanzado excesivo poder económico, pues favorecidas por la endémica oliganthropía poseen dos quintas partes de la tierra (utiliza el término gynaikokratoúmenoi, "gobernados por mujeres"); al proceso de concentración de la propiedad en pocas manos, potenciado igualmente por el paulatino descenso en el número de ciudadanos, mientras el tesoro público está vacío y el sistema tributario es ineficaz, por no decir inexistente ${ }^{45}$ al excesivo rigor del hilotismo, que incita a las sublevaciones y a la inestabilidad; y al militarismo desmedido (tema sobre el que vuelve en los libros VII y VIII), fruto de una mala comprensión de la areté, la cual no puede ser solo parcial, focalizada en una determinada virtud, la andreía, porque les lleva a creer que ésta es suficiente para asegurarse la hegemonía y, consecuentemente, a fomentarla en los jóvenes a través de penosos y excesivos ejercicios que no hacen sino embrutecerlos. ${ }^{46}$

41 En general para Esparta en el pensamiento aristotélico: Ollier 1933, 294-326; Cloché 1942; Tigerstedt 1965, 280-304; Rawson 1969, 72-80; De Laix 1974; David 1982-83; Schütrumpf 1994; Lévy 2001; Bertelli 2004; Hodkinson 2005, 227-237.

42 Ollier 1933, 270-271; Lévy 2005, 218.

43 Arist. Pol. 1294b14-18; cf. 1296a18-20. En otra obra aristotélica, la Ética a Nicómaco, el legislador espartano es elogiado por dos veces, primero junto a Creta, "por haber hecho a los ciudadanos buenos y sumisos a las leyes" (1102a8-12), y más adelante "por haberse interesado por la educación y las ocupaciones de los ciudadanos" (1180a25-30).

44 Arist. Pol. 1333b5-1334a10. Lo de Jano es de en Ollier 1933, 315

45 Ya lo reconoce el rey Arquidamo II en Th. 1.80.4: "no tenemos dinero en el tesoro público ni estamos en condiciones de obtenerlo fácilmente de los recursos privados".

46 Arist. Pol. 1269a29-1271b19, 1272a13-17, 37-39; cf. 1324b9, 1334a40-b3, 1338b9-13. Inciden sobre todo en esta crítica aristotélica los trabajos de Braun 1956 y Hermann-Otto 1998; aborda en concreto el análisis del imperialismo espartano, Schofield 2018. En palabras de Ollier 1933, 309, "Aristóteles traza el cuadro más severo y sin embargo más justo de la Esparta contemporánea de los que nos ha dejado el siglo IV” (trad. propia). 
Sobre el tipo de politeía, considera primero que Esparta es un estado en el que aparecen bien mezcladas democracia y aristocracia $(\delta \eta \mu о \kappa \rho \alpha \tau i ́ \alpha \varsigma \tau \varepsilon \kappa \alpha \grave{~} \alpha \rho \varepsilon \tau \tilde{\eta} \varsigma),{ }^{47}$ pero más adelante dice que combina democracia y oligarquía, pues es democrático el modo de educar a los niños por igual, la comida comunitaria (syssítion) y el que no se diferencie visualmente a ricos de pobres, mientras es oligárquico que todas las magistraturas sean electivas y que una minoría tenga en su mano las decisiones sobre la pena de muerte, el destierro y otros asuntos importantes ${ }^{48}$ para terminar por conceder importancia a la realeza, que ha aceptado limitaciones a su poder a cambio de hacerse más fuerte y duradera ${ }^{49}$ por más que le desagrade un principio hereditario que no sube al trono a los hombres más sabios y virtuosos. ${ }^{50}$ Precisamente porque estos regímenes coexisten a la vez, el Estagirita pone a Esparta como ejemplo de $\mu \varepsilon \mu \varepsilon \imath \gamma \mu \varepsilon \dot{\varepsilon} \eta \eta \pi \lambda \imath \tau \varepsilon i ́ \alpha$, aunque no sea perfecta, ${ }^{51} \mathrm{y}$ la sitúa entre las ciudades mejor administradas gracias a una Constitución que, junto a la cretense y la cartaginesa, "tiene con justicia buena reputación" y está muy por encima del resto. ${ }^{52}$

\section{Tratados sobre politeía y epitedeúmata lacedemonios}

Desgraciadamente no se nos ha conservado la Constitución de los lacedemonios salida de la escuela peripatética -sobreviven fragmentos de resúmenes hechos por Heraclides Lembo en el siglo II a.C.-, que sin duda hubiera sido una fuente de

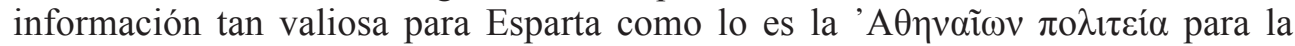
historia política e institucional de Atenas; claro que, salvo el ya mencionado de Jenofonte, no ha resistido la incuria del tiempo ninguno de los numerosos tratados constitucionales, o bien de usos y costumbres, que sobre Esparta se escribieron en la Antigüedad, reducidos a unas escasas citas, fundamentalmente en Ateneo y Plutarco. ${ }^{53}$ De los producidos en la misma Esparta no se ha conservado prácticamente nada de los lógoi políticos escritos por el rey Pausanias ${ }^{54} \mathrm{o}$ los harmostas Tibrón ${ }^{55} \mathrm{y}$ Lisandro, ${ }^{56}$ todos ellos a caballo entre los siglos V y IV. ${ }^{57}$ En cuanto a los que circularon más allá de las fronteras laconias, se perdieron las dos Lakedaimoniôn Politeíai, probablemente una en dísticos elegíacos y otra en prosa, de Critias, primo hermano de la madre de Platón y la cabeza visible y el más cruel de los Treinta Tiranos que gobernaron Atenas con el apoyo militar de Esparta tras la guerra del

47 Arist. Pol. 1293b14-18.

48 Arist. Pol. 1294b19-29.

49 Arist. Pol. 1313a19-33.

50 Arist. Pol. 1271a20-22.

51 Arist. Pol. 1265b33-36,1294b14-36; cf. Gianotti 2001, 23-27; Lévy 2001, 68-70; Hodkinson 2005, 236; Ducat 2017, 254-256.

52 Arist. Pol. 1272b26-29, 1273b24-26. De hecho, la polis lacedemonia parece inspirar algunos rasgos de la ciudad ideal aristotélica, una especie de "Esparta pacífica" (Ollier 1933, 324-325). De forma harto especulativa, Drews 1979 cree posible que las instituciones espartanas y cretenses, como las cartaginesas, estuvieran inspiradas en las fenicias, aunque admite que no sabemos apenas nada de éstas.

53 Para los autores antiguos atestiguados - sin duda hubo más- que escribieron sobre instituciones, tradiciones y costumbres lacedemonias, véase Figueira 2007.

$54 \quad F G H 582$; según Éforo (FGH 70 F118 apud Str. 8.5.5), el tratado era sobre la legislación de Licurgo ( $\pi \varepsilon \rho \grave{~} \tau \tilde{\omega} v$

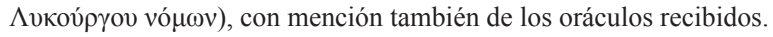

55 FGH 581; Arist. Pol. 1333b13-21.

56 Ephor. FGH 70 F207 apud Plu. Lys. 30.3-4.

57 Para estas obras, véase Tober 2010 y Lupi 2010. 
Peloponeso, para quien, según Jenofonte, condiscípulo en las enseñanzas socráticas y camarada en las filas oligárquicas, "la constitución de los lacedemonios parece en verdad la más hermosa ( $\alpha \alpha \lambda \lambda i ́ \sigma \tau \eta) "{ }^{58}$ Los pocos fragmentos que sobreviven ${ }^{59}$ permiten constatar su idolatría por costumbres espartanas como la moderación en el consumo de vino durante los syssítia, la frugalidad alimenticia, la sobriedad en el atuendo y en la educación, la procreación eugenésica o su aseveración, acaso de cuño socrático, de que "en Lacedemonia los hombres libres son más libres y los esclavos más esclavos". ${ }^{60}$

Dos escuetas menciones en Plutarco y Ateneo es lo único que tenemos de la

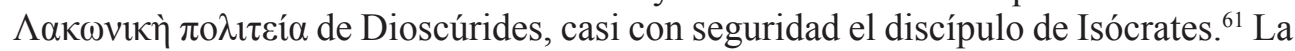

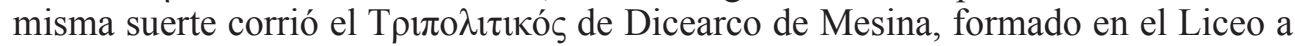
la sombra de Aristóteles y de Teofrasto, donde adquiría su formulación definitiva la teoría de la cuarta forma de gobierno (que él mismo denominó "la forma diceárquica"), esto es, la miktè politeía, tripartita, atemperada, ideal, ${ }^{62}$ de la que Esparta se erigía en arquetipo; de su opúsculo sobre la $\pi$ o $\lambda \imath \tau \varepsilon i ́ \alpha \Sigma \pi \alpha \rho \tau \imath \alpha \tau \tilde{\omega} v$, seguramente parte de su

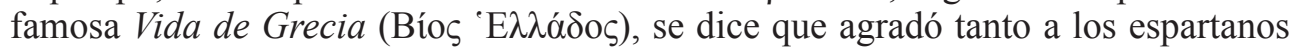
que cada año era objeto de lectura pública en el ephorê̂on, la sede de los éforos. ${ }^{63} \mathrm{El}$ pitagórico Arquitas de Tarento, amigo de Platón y algo anterior a Dicearco, también

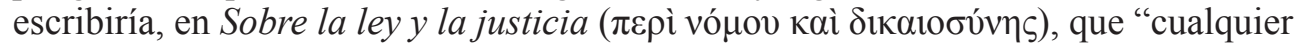
legislación que quiera ser poderosa y longeva, así como la ciudad, debe estar compuesta de instituciones democráticas, oligárquicas, monárquicas y aristocráticas. Es lo que sucede precisamente en la bien reglada Lacedemonia: los reyes representan a la monarquía, los gérontes a la aristocracia, los éforos a la oligarquía y los hippagrétai y los hippeîs a la democracia; cada cargo gobierna y a la vez es gobernado", ${ }^{64}$ bien que en este caso el equilibrio y reciprocidad entre ellos se ajustaba a los principios pitagóricos de las fuerzas naturales que se contrarrestan. La huella espartana es asimismo bien patente en las hechuras de las escuelas cínica y estoica. ${ }^{65}$ Según Plutarco, sus precursores, Diógenes de Sínope y Zenón de Citio, se habrían inspirado en la legislación licurguea para sus respectivas politeíai. ${ }^{66}$

\section{Isócrates}

A la enseñanza de la retórica y no al pensamiento político dedicó su larga vida Isócrates, que mediada la década del 360 escribe su Arquidamo con aparente empatía hacia una Esparta que, aplastada en Leuctra por los tebanos y ahora aliada

\footnotetext{
X. $H G$. 2.3.34 (trad. propia).

Frg. 88B32-37 Diels-Kranz.

Frg. 37, preservado en Lib. 25.63 (trad. propia).

Plu. Lyk. 11.9; Ath. 140B y F.

Frg. 71 Wehrli.

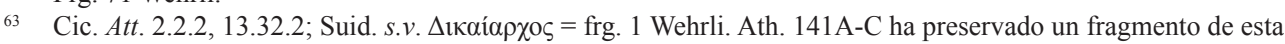
obra a propósito de la sencillez que, cada noche, presidía la celebración del syssition.

64 Stob. 4.1 .38 (trad. propia). De Arquitas cuenta también Estobeo (4.1.38) que recomendaba que "las leyes no deben ser grabadas en casas o puertas, sino en el corazón de los ciudadanos, igual que la bien reglada ciudad de Esparta no se gobierna con una abundancia de leyes escritas".

65 Ollier 1943, 3-20, 76-123; Tigerstedt 1974, 30-48.

66 Plu. Lyk. 31.2. D.L. 7.33 y 131 asegura que en la suya Zenón auspiciaba la igualdad entre los sexos, el comunismo de bienes y sexual y la abolición de la moneda.
} 
de Atenas, ha perdido Mesenia y, con la tierra, los hilotas que la trabajaban; en el discurso se anima a los espartiatas a recuperar este territorio vecino "adquirido con no menos justicia que el resto de Lacedemonia" ${ }^{67}$ apelando por un lado a la ancestral tradición del retorno de los Heraclidas, sobre la cual se cimenta en el imaginario mítico la legitimidad espartana a la hegemonía peloponésica, y por otro a los atributos que siempre les han caracterizado, su pericia militar y su inalterable ordenamiento político, que es comparado con un campamento militar bien regulado, ${ }^{68}$ una imagen que evoca también su contemporáneo Platón ${ }^{69}$ y que será recurrente en la historia del pensamiento occidental. Pero todo ello en un discurso ficticio puesto en boca de un joven príncipe espartiata, el hijo de Agesilao II y futuro Arquidamo III, dirigiéndose a la Asamblea lacedemonia, con lo que no cabría esperar menos. ${ }^{70}$

Tampoco están claras las intenciones de Isócrates en el Busiris, no solo por el tono paródico que se cierne sobre este elogio del mítico rey egipcio denostado por la tradición helénica, sino porque allí la aserción de que los lacedemonios "administran muy bien su ciudad" tras haber adoptado ciertos elementos constitucionales egipcios (las comidas públicas, el ejercicio físico, las actividades militares, el no descuidar los preceptos del Estado) es desacreditada enseguida por el hecho de que no hacen buen uso de estas costumbres, pues, llevados de su pereza y ambición, "creen justo apoderarse de lo ajeno por la fuerza" ${ }^{71}$ El discurso se data hacia 385 , cuando la paz del Rey legitimó un nuevo orden internacional auspiciado por Esparta.

En el Nicocles, un encomio del rey chipriota, hijo de Evágoras de Salamina, los lacedemonios vuelven a aparecer como "el pueblo mejor gobernado entre los griegos", porque, lo mismo que los cartagineses, tienen una oligarquía como sistema político en casa que es compatible con la monarquía que rige en la guerra. ${ }^{72}$

En Areopagítico, Isócrates alaba en diversas ocasiones el pasado y las virtudes de Esparta, un elogio que se incardina en un canto a la pátrios politeía de los antepasados, personificada en un tribunal del Areópago que, cual espejo de la

67 Isocr. 6.16 (seguimos aquí, siempre que no se indique lo contrario, la trad. J. M. Guzmán Hermida, BCG, 1979-1980). En Panegírico (131), del año 380, Isócrates ya admitía la hilotización de los mesenios. El punto de vista opuesto, el de que Atenas no debe ayudar a Esparta a recuperar Mesenia, pues es justo que ésta sea libre, es mantenido por Demóstenes en el discurso En defensa de los megalopolitanos (esp. 9, 12 y 25), pronunciado en 353, y por un Alcidamas (frg. 1 A., preservado en el anónimo Comentario a la Retórica de Aristóteles) que proclama que el dios ha dado a todos los hombres la libertad y que la naturaleza no ha hecho a nadie esclavo.

68 Isocr. 6.81.

69 Pl. $L g .666$ e, referido en principio a Creta.

70 Ya desde la Antigüedad se pensó que era una declamación de escuela que servía de modelo para los discípulos, hipótesis que han seguido algunos estudiosos modernos; Harding 1973, por ejemplo, considera que este discurso y Sobre la paz con los lacedemonios son meros ejercicios retóricos que conforman una antilogía, opiniones contrapuestas; según Azoulay 2006, el discurso explora un tema de teoría política, el de la relación de una ciudad con su territorio. Para Cloché 1933, 134-136, Isócrates es sincero en su elogio de Esparta, mientras que Ollier 1933, 360-363, supedita el deseo de ayudar a Esparta al odio que Isócrates sentía por los tebanos, beneficiarios de las desgracias lacedemonias y atenienses. Cf. también Bouchet 2014, 60-66, para quien las ambiciones de Esparta se limitan a la recuperación de Mesenia y la nostalgia de su pasada hegemonía trasluciría en realidad un deseo de recuperación de la hegemonía ateniense. No debe olvidarse que en 356 Isócrates hará del mismo Arquidamo, por entonces ya rey y con cierto prestigio militar, el destinatario de una carta (la IX) en la que le anima a realizar hazañas panhelénicas, es decir, del tenor del discurso y las dos cartas que más tarde dedicará a Filipo II.

71 Isocr. 11.17-20.

72 Isocr. 3.24 . 
Gerousía, hacía imperar la virtud y el buen orden, de modo que la Constitución ancestral ateniense se vincula con la "igualitaria y homogénea demokratía espartana". ${ }^{73}$

Y en Sobre la paz con los lacedemonios, una reflexión sobre el fracaso del imperialismo escrita tras una guerra de los aliados que vio en 355 la desintegración de la segunda confederación ateniense, la admiración por el ordenamiento político y las tradicionales virtudes espartanas se engarza con las críticas por la pereza, el desdén por la ley y la pleonexía (codicia) en la que han caído, además de haberse vendido al bárbaro y haber ejercido una violencia desmedida, contraria a juramentos y acuerdos, durante su imperio marítimo, responsable éste en última instancia de la ruina del bien asentado y firme imperio continental de antaño. ${ }^{74}$ Así, "dejaron de guardar las leyes que recibieron de sus antepasados y de mantener las costumbres que antes tuvieron", ${ }^{75}$ con lo que, sentencia Isócrates, "su Constitución política, que nadie sabe que en setecientos años hubiera sido alterada ni por situaciones de peligro ni por desgracias, en breve tiempo se tambaleó y faltó poco para que fuera destruida". ${ }^{76}$

En su último discurso importante, el Panatenaico, una glorificación del pasado de Atenas que data de 339, el anciano rétor sin tribuna recurre a una comparación con la ciudad de los espartiatas, "que la mayoría elogia con mesura, aunque algunos la recuerdan como si allí hubieran gobernado semidioses". ${ }^{77}$ Según Isócrates, el ordenamiento espartano imita de la mejor manera posible el de los antepasados de los atenienses en tanto en cuanto mezcla la democracia con la aristocracia o gobierno de los mejores, y así por ejemplo la elección de los gérontes se hace con el mismo escrúpulo con que se hacía la de los areopagitas, ${ }^{78}$ pero más adelante censura las injusticias y la brutalidad de los espartiatas para con los demás griegos en el exterior y con sus grupos dependientes en el interior ("el coraje guerrero pertenece a menudo a los más criminales de los hombres"), reservando la democracia y la igualdad de

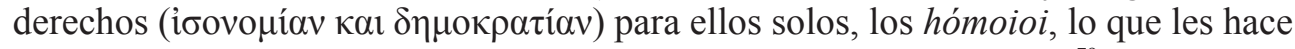
inferiores a unos atenienses más altruistas para con los otros griegos; ${ }^{79}$ en el último tercio del discurso, en medio de complicadas piruetas retóricas, da cumplida réplica al encomio de los hábitos y ocupaciones (epitedeúmata) de los espartiatas verbalizado por un (supuesto o real) discípulo suyo simpatizante de Esparta. ${ }^{80}$ Por entonces los

73 Isocr. 7.61 (trad. propia). Como bien anota Canfora 1990, 10, "Isócrates capta un elemento sustancial: en ambas comunidades la sede de la soberanía es la misma. Es la asamblea de varones libres adultos. En ambas comunidades (...) el cuerpo que toma las decisiones es el cuerpo combatiente" (trad. propia).

74 Isocr. 8.95-104. Como ha expresado David Asheri 2000, 193, a lo largo de la obra de Isócrates aflora "la antítesis moral de que, frente a una arché terrestre que, ejercida con moderación ( $\sigma \omega \varphi \rho o \sigma u ́ v \eta)$ y buen orden ( $\left.\varepsilon \dot{\tau} \tau \alpha \xi^{\prime} \alpha\right)$, es meritoria, la arché naval, al no requerir de cualidades morales propias y basarse puramente en la destreza y habilidad de las tripulaciones, se distingue por su falta de regulación ( $\dot{\alpha} \kappa o \lambda \alpha \sigma i ́ \alpha)$, injerencia ( $\pi \mathrm{o} \lambda v \pi \rho \alpha \gamma \mu о \sigma v ́ v \eta)$ e insolencia (v̋ $\beta \rho \iota \varsigma)$; un dominio que puede convertirse en inmoral, tiránico y fuente de graves errores y de autodestrucción". Desde otros planteamientos, según Bouchet 2014, 72-81, 195-210, en un discurso que es todo menos pesimista, Isócrates continúa deseando la preeminencia de Atenas en Grecia, pero bajo la forma de una "bella" hegemonía y no de un imperio, asumiendo el papel de jefes y no de tiranos.

75 Isocr. 8.102.

76 Isocr. 8.95. Tal afirmación llevaría inverosímilmente hasta el siglo XII la politeía lacedemonia.

77 Isocr. 12.41 .

78 Isocr. 12.153-154.

79 Isocr. 12.177-181, 198 (trad. propia); cf. 45-46, 65-66, 104.

80 Isocr. 12.200-265. 
espartanos ya habían enseñado a Isócrates que no compartían en absoluto sus ideales panhelénicos, personificados ahora en ese nuevo Agamenón que es Filipo II de Macedonia. ${ }^{81}$

\section{Historiografía "retórica"}

Un supuesto discípulo de Isócrates - tal magisterio, antaño aceptado, puede haber sido una construcción helenística- fue Éforo, quien construyó su Historia Universal como una sucesión de hegemonías, de ascenso y caída de estados que seguía un criterio geográfico y que respondía a una combinación de factores políticos y morales. Por esta razón otorgó enorme importancia a un ordenamiento sociopolítico que el mítico Licurgo tomó de la no menos mítica Creta de los reyes Radamantis y Minos -luego sancionado por Apolo en Delfos, como ya se ha dicho- y que a su vez sirvió de inspiración para las leyes que el legendario Zaleuco dio a los locrios; ${ }^{82}$ sobre ese orden licurgueo se cimentó la hegemonía espartana, en la medida en que fomentó el valor, la disciplina, la moderación y el sentido comunitario entre la ciudadanía, al tiempo que erradicaba el individualismo, el lujo y la avaricia; ${ }^{83}$ a través de la amable concordia, el espartiata recorría el camino que conducía hasta la morada de la eleuthería, evitando aquel otro que, a través de la odiosa discordia, llevaba hasta la casa de la douleía, tal y como aconsejó a Licurgo el oráculo délfico ${ }^{84}$ Naturalmente el fracaso hegemónico de Esparta queda explicado por la degeneración y el abandono de estas virtudes tradicionales tras la victoria en la guerra del Peloponeso, una de cuyas plasmaciones fue la injusticia, la opresión y las exacciones sobre sus aliados. ${ }^{85}$ El historiador minorasiático parece añorar los días de aquella Esparta virtuosa y triunfante, contribuyendo así a la consagración del mito impulsado por Jenofonte y Platón. ${ }^{86}$

La tradición hace también discípulo de Isócrates, y por ello otro ejemplo relevante de una historiografía retórica y cargada de juicios morales, a Teopompo de Quíos, hijo de Damisístrato, un aristócrata expulsado de la isla por laconismo. ${ }^{87} \mathrm{Nada}$ ha quedado de su discurso Lakonikós, ${ }^{88}$ pues en sus inicios trabajó como logógrafo, pero sí contamos con fragmentos de sus dos obras mayores, las Historias Filípicas y las Helénicas, de los que se infiere un cierto perfil laconizante: si la democracia ateniense y sus demagogos reciben duros ataques, ${ }^{89}$ la hegemonía espartana en

81 Isocr. 12.72-86. Un mayor desarrollo de los argumentos aquí expuestos se puede encontrar en Cloché 1933; Ollier 1933, 326-371; y, últimamente, Cataldi 2007. En concreto para el Panatenaico, véase Gray 1994. En cuanto al ideario político de Isócrates, Sancho Rocher 2008 defiende la tesis de que, más que conservador, moderado o monárquico, fue un corrector de la democracia, especialmente a través de la propuesta del cambio en la dirección política, que debía sustraerse a los demagogos.

82 Str. 6.1.8; 10.4.19. Éforo es el primero que intenta dotar de rasgos biográficos a la figura de Licurgo (cf. Ollier 1943, 69, seguido por David 2007, 307).

83 Cf. Plb. 6.46.6-8.

84 D.S. $7.12 \cdot 2-4$

85 D.S. $7.12 .8,14.2 .1,14.10 .2,15.2-5$.

86 Sobre la recepción de Esparta en la obra de Éforo, véase Ollier 1943, 66-74; Tigerstedt 1965, 208-222; Hodkinson 1994, 196-200; 2000, 27-28; y, últimamente, Christesen 2010, quien combate la opinión predominante en la historiografía moderna en cuanto a que el de Cime "sacrificó la verdad para construir parádeigmata morales que incitan al lector a la virtud" (Christesen 2010, 243, trad. propia).

$87 \quad F G H 115$ T2.

88 FGH 115 T48.

89 FGH 115 T85-100, 122, 321-323. 
Grecia en cambio es presentada de manera favorable, sin escatimar elogios a las virtudes -severidad, moderación, sagacidad, sentido del deber $\mathrm{y}$, sobre todo, desprecio de la corruptora tryphé- de líderes espartiatas como Agesilao y, más extrañamente, Lisandro, ${ }^{90}$ aunque reserva también críticas a la conducta de otros como Fárax ${ }^{91}$ o a "la absolutamente cruel y amarga situación en que se halla el pueblo de los hilotas". ${ }^{92}$ Teopompo creía que Esparta era un reducto aristocrático y arcaizante que aún atesoraba las viejas y queridas costumbres de antaño. ${ }^{93}$

\section{Polibio}

En época helenística tenemos noticia de ciertos autores, algunos de ellos de origen lacedemonio, que escribieron sobre la $\pi$ o $\lambda \iota \tau \varepsilon i ́ \alpha$ espartana o bien $\Lambda \alpha \kappa \omega v \iota \kappa \alpha ́$, pero apenas son nombres y las dataciones resultan demasiado aventuradas. ${ }^{94}$ En cualquier caso, será Polibio en el siglo II, especialmente en su libro VI, quien se erija en el gran sistematizador de la teoría del ordenamiento constitucional mixto. ${ }^{95}$ Roma y Cartago se suman entonces a Esparta y Creta en la nómina de estados cuya expansión política y militar se explica por el buen gobierno, cimentado en un equilibrio de regímenes

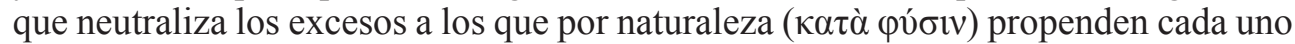
-la anakýklosis o ciclo degenerativo de las formas de gobierno, posiblemente una originalidad polibiana $-{ }^{96}$ para dar como resultado la $\alpha \rho i ́ \sigma \tau \eta ~ \pi o \lambda ı \tau \varepsilon i ́ \alpha$, el ordenamiento constitucional óptimo: los cónsules -y en Cartago los sufetes- encarnan la realeza, el Senado la oligarquía y, por último, el pueblo, organizado en las distintas asambleas, la democracia. El pasaje clave sobre Esparta merece citarse in extenso:

Con cada una de las constituciones nace una cierta enfermedad que se sigue de ella naturalmente. Con la realeza nace el desmejoramiento llamado tiranía; con la aristocracia, el mal llamado oligarquía, y con la democracia germina el salvajismo de la fuerza bruta. Y es inevitable que con el tiempo todos los regímenes citados anteriormente degeneren en sus inferiores. Licurgo lo previó y promulgó una institución no simple ni homogénea, sino que juntó en una las peculiaridades y virtudes de las constituciones mejores. Así evitaba que alguna de ellas se desarrollara más de lo necesario y derivara hacia su desmejoramiento congénito; neutralizada por las otras la potencia de cada constitución, ninguna tendría un sobrepeso ni prevalecería demasiado, sino que, equilibrada y sostenida en su nivel,

$90 \quad F G H 115$ T20, 22, 321, 333.

$91 \quad F G H 115$ T192.

92 FGH 115 T13 y 122 apud Ath. 265B-C y 272A (trad. L. Rodríguez-Noriega Guillén, BCG, 2006).

93 Véase Ollier 1943, 63-66; Tigerstedt 1965, 222-225; Rawson 1969, 54-55. Hodkinson 2005, 223, califica el laconismo de Teopompo, como el de Éforo, de "nostálgico", frente a otras clases de laconismo (social, político, filosófico) identificadas por Cartledge 1999, 313-314.

94 Ollier 1943, 126-128. Existió una historiografía local menor (véase Thommen 2000), de entre la cual Sosibio (tradicionalmente datado entre los siglos III y II, pero a quien ahora Lévy 2007 lleva hasta el I a.C. o el I d.C.) es el único que gozó de cierto reconocimiento y de cuyas obras restan unos fragmentos (FGH 587, 589-592, $595)$ que se refieren a religión, costumbres y vocabulario de los espartanos, pero curiosamente ninguno alude a la originalidad de la politeía lacedemonia.

95 Plb. 6.3.5-8, 6.10.4-11, 6.11.11, 6.48-50. Véase: Fritz 1954; Walbank 1966; Gräber 1968; Lévy 1987, 64-71; Martínez-Lacy 2005.

96 Sobre la cual: Díaz Tejera 1975; Alonso-Núñez 1986; Podes 1991. Según Ollier 1943, 159, Polibio no hace sino beber de los lugares comunes de la cultura helenística. 
se conservaría en este estado el máximo tiempo posible. La realeza no podía ensoberbecerse por temor al pueblo, porque a éste se le había concedido competencia suficiente en la constitución; el pueblo, por su parte, no podía aventurarse a despreciar a los reyes por el miedo que le infundían los ancianos, quienes, elegidos por votación, según sus méritos, se aprestaban siempre a decidir con justicia. Así la parte venida a menos, debido a que se mantuvo fiel a sus normas, acabó por convertirse en superior y más fuerte por el soporte que recibía de los ancianos. Licurgo, pues, estructuró así la constitución espartana y la aseguró entre los espartanos el tiempo más largo que conocemos. ${ }^{97}$

Más adelante, Polibio cita a los lacedemonios a la cabeza de los pueblos con

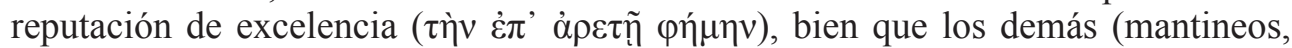
cretenses, tebanos, atenienses) solo disfrutaron de una prosperidad repentina y coyuntural y únicamente los espartanos se dotaron de un ordenamiento constitucional digno de compararse con el romano. ${ }^{98}$ Ya Heródoto, Tucídides e Isócrates subrayaron que los lacedemonios conservaban desde antiguo una gran estabilidad constitucional, ${ }^{99}$ que Lisias en su Discurso olímpico atribuye a que los espartanos se habían visto siempre libres de conflictos internos (astasíastoi), ${ }^{100}$ una idea a la que se suma Polibio cuando dice que "se gobiernan a sí mismos con un hermoso entendimiento y siempre están de mutuo acuerdo". ${ }^{101}$ En cuanto garantes de la concordia interna, de la seguridad del territorio y de la libertad de los ciudadanos, las instituciones licurgueas casi le resultan "de origen divino más que humano". ${ }^{102}$ La Gerousía o Consejo de ancianos, travestida de Senado romano, es para Polibio la piedra angular del sistema en detrimento de unos éforos que son conscientemente olvidados-vivos aún los violentos acontecimientos que protagonizaron a finales del siglo anterior-, pues son los magistrados supremos y no el pueblo quienes en realidad ejercen el control de los reyes. ${ }^{103} \mathrm{La}$ excelencia política tiene, para el historiador helenístico, su correspondencia en la esfera social y moral, a la que Esparta aporta un cuerpo de ciudadanos homogéneo en riqueza y en virtud que se contrapone al cretense, donde las desigualdades hacen que impere el conflicto interno; ${ }^{104}$ en este sentido, Polibio es, cronológicamente, la primera fuente preservada en acoger la idea de una igualdad económica y de propiedades entre los espartiatas. ${ }^{105}$

Pero si dentro de Esparta sus instituciones y dictados promovían el coraje ( $\alpha v \delta \rho \varepsilon i ́ \alpha)$, la moderación ( $\sigma \omega \varphi \rho \circ \sigma u ́ v \eta)$ y la concordia (ó $\mu o ́ v o l \alpha)$, formando ciudadanos valientes y nobles y dificultando el nacimiento de la ruindad, no ocurría lo mismo en su relación

97 Plb. 6.10.4-11 (en las citas de este autor seguimos la trad. de M. Balasch Recort, BCG, 1981, aquí ligeramente modificada).

98 Plb. 6.43-44. Es conocida la condena que Polibio hace aquí del régimen democrático ateniense, al que compara con una nave a la deriva por el desacuerdo y la anarquía que reina entre los marineros, desdeñosos de obedecer a su capitán.

99 Hdt. 1.65.2-66.1; Th. 1.18.1; Isocr. 8.95.

100 Lys. 33.7.

101 Plb. 6.46.7-8.

102 Plb. 6.48.2.

103 Lévy 1987, 66-69, que hace notar la paradoja de que, obviando a los éforos, Polibio acaba por dar la razón a los reyes que él condena como revolucionarios y tiránicos por haber coartado o suprimido el poder de los magistrados.

104 Plb. 6.48.3.

105 Detalle importante que es subrayado por Hodkinson 2000, 50-52. 
con los demás griegos, porque Licurgo careció de un proyecto que evitara que los

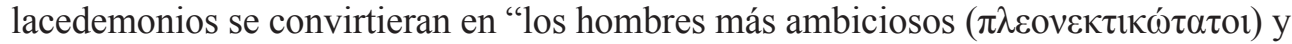

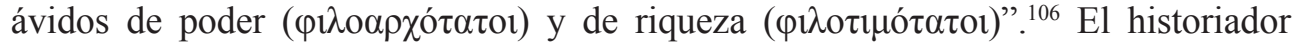
arcadio ilustra tal afirmación con un excurso en el que expone que la ambición por dominar a otros griegos llevó a los espartanos primero a la conquista de Mesenia y luego, para sustentar un imperio de ultramar con los recursos de un estado campesino, a imponer tributo a los helenos y a humillarse ellos ante los persas (en la Paz del Rey, en 386) pese a que les habían vencido en el campo de batalla (en Platea, año 479), todo por obtener dinero con que construir y equipar flotas. ${ }^{107}$ En otras palabras, Licurgo no previó, y por lo tanto no legisló, para una hegemonía (philoarchía) y un imperio territorial, fracasando, lo mismo que los atenienses, allí donde Roma triunfó. ${ }^{108}$ A esta crítica descarnada de la política exterior lacedemonia no es ajeno, naturalmente, el hecho de que Esparta haya sido durante mucho tiempo la enemiga de la liga aquea, a la que pertenecía Megalópolis, su ciudad natal, y en la que tanto él como su padre, Licortas, habían sido hiparcos y embajadores (y su padre también strategós). Este retrato del carácter espartiata es pues sesgado, sobre todo si se tiene en cuenta que tanto Platón como Aristóteles consideraron que la ambición y la búsqueda de honores, fundamentalmente a través de la guerra, son rasgos propios de los hómoioi desde los tiempos de Licurgo; ${ }^{109}$ lo que sucede en realidad es una falta de adecuación entre las perspectivas imperiales de Esparta y sus recursos materiales y humanos, cosa que por el contrario no se produce en el caso romano. ${ }^{110}$

Incluso en el orden interno la situación se pervertiría. En el libro IV, Polibio reitera que Licurgo hizo muy poderosos a los lacedemonios al darles un excelente

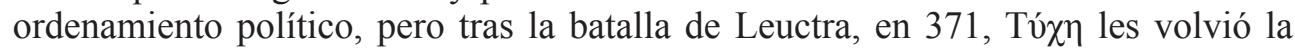
espalda, comenzaron a experimentar penalidades, luchas civiles, distribuciones de tierra, proscripciones y hasta probaron la esclavitud más amarga bajo Nabis. ${ }^{111}$ En un pasaje anterior, esta vez del libro I, la hegemonía espartana se reduce a apenas doce años, los que median entre la batalla de Egospótamos en 405 y la derrota de Cnido en $394,{ }^{112}$ si bien cabe decir que debe entenderse una hegemonía indiscutible, naval y terrestre -el historiador Teopompo ya vio en Cnido el punto de inflexión con el que cerrar sus Helénicas- ${ }^{113}$ ya que en el continente los lacedemonios continuaron su primacía hasta la débâcle de Leuctra. En Polibio, por tanto, Esparta sufre un descalabro político y militar, sin asomarse siquiera a las raíces del mismo, a la desnaturalización de las instituciones y costumbres espartiatas o al fracaso de éstos en regenerar el cuerpo cívico.

Se ha hecho notar, asimismo, lo aparentemente contradictorio de que Polibio, tan entusiasta de la legislación de Licurgo, se mostrara hostil al rey Cleómenes III, cuyas casi contemporáneas reformas atávicas pasaban por buscar un restablecimiento del kósmos licurgueo. ${ }^{114}$ Es más, para Polibio Cleómenes abatió la Constitución ancestral

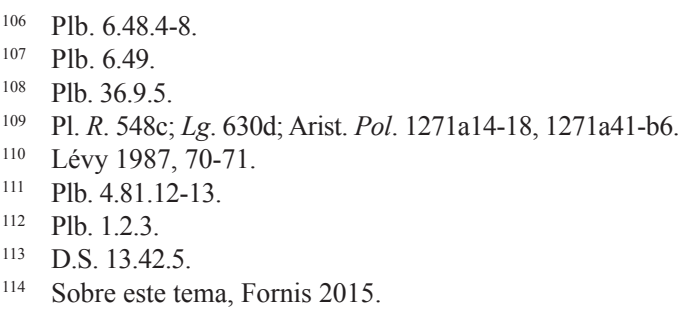


( la libertad ( $\dot{\varepsilon} \lambda \varepsilon v \theta \varepsilon \rho i ́ \alpha)$, por el monarca macedonio Antígono Dosón. Más allá de que el espartano asolara Megalópolis con particular saña, ${ }^{115}$ Walbank ha incidido en que Polibio no ve en Cleómenes a un rey, sino a un tirano que ha abolido la eforía y la diarquía para gobernar en solitario, ${ }^{116}$ a lo que seguramente cabría añadir las cancelaciones de deudas y las confiscaciones y redistribuciones de propiedad, medidas aplicadas frecuentemente por los tiranos y que en este caso Cleómenes pretendió extender por el Peloponeso, subvirtiendo el orden establecido. ${ }^{117}$ Lévy lo percibe, desde otro punto de vista, como un conflicto entre gobernarse de acuerdo

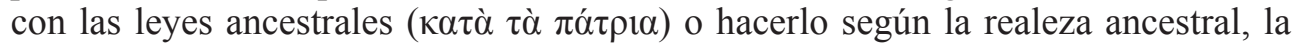

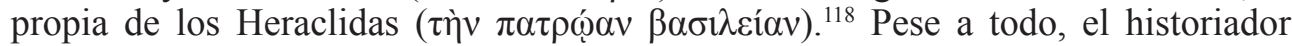
megalopolitano nunca utiliza el término túpavvos aplicado a Cleómenes, porque no puso en duda su legitimidad al trono, ni sus dotes como jefe del pueblo en armas -de hecho, es de nuevo Fortuna quien interviene, para su fatalidad, en la batalla de Selasia-, y el valor y sus cualidades estratégicas son destacadas a modo de breve elogio fúnebre. ${ }^{119}$ Reservó su hostilidad para Licurgo II, cuya ascendencia real, su condición de Heraclida, es puesta en tela de juicio ${ }^{120}$ tanto como la eficacia de sus campañas militares, y sobre todo para Nabis, verdadero arquetipo de tirano demagogo, que persigue y mata a los ciudadanos distinguidos, confiscando sus propiedades, mientras sustenta su poder, violento y cruel, en esclavos manumitidos y gente de la peor calaña, incluidos los mercenarios -criminales, según Polibio-que contrata para su protección. ${ }^{121}$

\section{Cicerón y el final de la reflexión teórica sobre la Constitución mixta}

En el siglo siguiente, todavía Cicerón se dejará seducir por la teoría de la Constitución mixta en Sobre la república, donde la base de la estabilidad de la república romana pasa por "un equilibrio de derecho, deber y poder, de manera que los magistrados tengan la suficiente potestas, el Consejo de los hombres principales la suficiente auctoritas y el pueblo la suficiente libertas". ${ }^{122}$ El orador de Arpino traduce así a principios de gobierno lo que para los griegos eran formas de gobierno, de politeíai. ${ }^{23} \mathrm{Al}$ mirar al pasado para explicar el engrandecimiento de Roma, Rómulo se habría inspirado en Licurgo y, como él, vio que las ciudades se gobiernan mejor si el poder real se complementa con la autoridad de los mejores. ${ }^{124}$ No obstante, Cicerón matiza que la monarquía ha de ser electiva, como la romana, y no hereditaria, como la espartana, porque "conviene buscar el valor y la sabiduría de un rey, no la

\footnotetext{
115 Plb. 2.55.7-8.

116 Plb. 9.29.8, 9.36.4, 23.11.4-5.

117 Walbank 1966, 304-305.

118 Lévy 1987, 69.

119 Plb. 5.39.6; cf. Lévy 1987, 71-74. Será Pausanias quien vaya más allá al exculpar a los espartanos de la destrucción de Megalópolis y cargar toda la responsabilidad en un Cleómenes que, aquí sí, "había transformado su ordenamiento político de monarquía en tiranía" (8.27.16).

120 Plb. 4.35.13-15, donde paga un talento por el trono.

121 Plb. 13.6.1-6, 16.13.1; cf. Lévy 1987, 74-78. Sobre Nabis: Fornis 2016.

122 Cic. Resp. 2.33.57 (seguimos siempre la trad. de A. D’Ors, BCG, 1984); cf. 39.65.

123 Morel 1996, 101.

124 Cic. Resp. 2.9.15.
} 
estirpe", ${ }^{125}$ mientras que el Consejo de Notables no ha de ser tan reducido, igual que el Senatus es más numeroso que la Gerousía sobre la que se modela y de cuyo nombre mismo es traducción. ${ }^{126}$ Aun con todo, la realeza continuará sobresaliendo y el Estado no dejará de ser un reino, con el pueblo sometido y sin libertad, razón por la cual ni Esparta ni Cartago ni la Roma prerrepublicana combinaron adecuadamente y con moderación las tres formas de gobierno. ${ }^{127}$ En el presente, como sentencia en el Pro Murena, la preservación de las leyes y costumbres de los lacedemonios -el único pueblo del mundo que las ha mantenido inalterables durante setecientos años, ${ }^{128}$ una afirmación tan henchida de mirage como la de Isócrates-solo es posible al amparo de la autoridad y la protección de Roma. ${ }^{129}$

Con el advenimiento de la autocracia imperial, la teoría de la miktè politeía comienza a dejar de tener sentido, por motivos obvios. Aún hallamos una suerte de reformulación, de adaptación a los nuevos tiempos, en Dionisio de Halicarnaso, quien presenta a sus lectores que los paradigmas griegos están agotados y solo una "mímesis selecta" de ellos podría contribuir a mejorar lo que de hecho es una creación constitucional de los romanos, explicándose así la superioridad de éstos sobre el resto de los pueblos de la ecúmene y, en definitiva, la legitimación de su imperio. ${ }^{130}$ Pero ya Tácito la condena de manera irremisible: "Una forma de Estado mixta es más fácil de alabar que de establecer, y si se establece, no puede ser duradera". ${ }^{131}$ El paradigma será resucitado, sin embargo, por los humanistas y utópicos renacentistas ${ }^{132} \mathrm{y}$, con Esparta casi siempre en la sombra, estará llamado a conocer gran fortuna en el pensamiento político moderno, ${ }^{133}$ no siendo pocos los que han visto en este constructo ideal, en este fantasma político, un lejano precedente del sistema de checks and balances del mundo anglosajón. ${ }^{134}$ Pero eso queda mucho más allá del límite cronológico que nos hemos trazado.

\section{Referencias bibliográficas}

Alonso-Núñez, J. M. (1986): “The Anacyclosis in Polybius”, Eranos 84, 17-22.

Asheri, D. (2000): “Isocrate e l'impero", [en] E. Luppino Manes (a.c.), Egemonia di terra ed egemonia di mare. Tracce del dibattito nella storiografia tra V e IV sec. a.C. (=Collana del Dipartimento di scienze dell'antichità dell'Università degli studi G. D'Annunzio. Sezione di Storia 4), Alessandria, 193-201.

Azoulay, V. (2006): “L'Archidamos d'Isocrate: une politique de l'espace et du temps", Revue des Études Grecques 119, 504-531 (https://doi.org/10.3406/reg.2006.4672).

Bertelli, L. B. (2004): "La Sparta di Aristotele: un ambiguo paradigma o la crisi d'un modello?", Rivista Storica dell'Antichità 34, 9-71.

125 Cic. Resp. 2.12.24; cf. 1.33.50.

126 Cic. Resp. 2.28.50.

127 Cic. Resp. 2.23.42-43.

128 Cic. Flacc. 63.

129 Cic. Mur. 74.

130 Wiater 2018, esp. 219-227, que concluye que el Halicarnasio fue pragmático en la representación de un nuevo tipo de helenismo.

131 Tac. Ann. 4.33.1 (trad. J. L. Moralejo, BCG, 1979).

132 Fornis 2012.

133 Con carácter general, Rawson 1969 y Morel 1996.

134 Un reciente trabajo de Jean Ducat (2017) reivindica, en nuestra opinión con argumentos demasiado forzados, que la politeía lacedemonia continúa siendo mixta desde la perspectiva de los estudiosos en Ciencia Política de hoy en día. 
Birgalias, N. - Buraselis, K. - Cartledge, P. (eds.), (2007): The Contribution of Ancient Sparta to Political Thought and Practice, Athens.

Bouchet, C. (2014): Isocrate l'Athénien, ou la belle hégémonie. Étude des relations internationales au IVe siècle a.C. (=Ausonius Éditions. Scripta Antiqua 60), Bordeaux.

Braun, E. (1956): "Die Kritik der lakedaimonischen Verfassung in der Politika des Aristoteles", Kärntner Museumsschriften 12, 5-36.

Canfora, L. (1990): "Nota”, [en] G. F. Gianotti (a.c.), Senofonte. L'ordinamento politico degli Spartani, Palermo, 9-13.

Cartledge, P. (1999): “The Socratics' Sparta and Rousseau's”, [en] S. Hodkinson - A. Powell (eds.), Sparta. New Perspectives, London, 311-337 (https://doi.org/10.2307/j. ctvvn9cq.14).

Cartledge, P. - Powell, A. (eds.), (2018): The Greek Superpower: Sparta in Self-Definitions of Athenians, Swansea (https://doi.org/10.2307/j.ctv5jxmb3).

Cataldi, S. (2007): "Isocrate e la Lakedaimonion Politeia. Spunti per una riconsiderazione", [en] Birgalias et alii (eds.), 2007, 247-260.

Christesen, $\mathrm{P}$.

(2010): "Spartans and Scythians, a Meeting of Mirages: The Portrayal of the Lycurgan Politeia in Ephorus' Histories", [en] A. Powell - S. Hodkinson (eds.), Sparta: The Body Politic, Swansea, 211-263 (https://doi.org/10.2307/j.ctvvn9tj.9).

(2017): "Xenophon's Views on Sparta", [en] M. Flower (ed.), The Cambridge Companion to Xenophon, Cambridge, 376-400 (https://doi.org/10.1017/9781107279308.022).

Cloché, P.

(1933): “Isocrate et la politique lacédémonienne", Revue des Études Anciennes 35, 129145 (https://doi.org/10.3406/rea.1933.2694).

(1942): “Aristote et les institutions de Sparte", Les Études Classiques 11, 289-313.

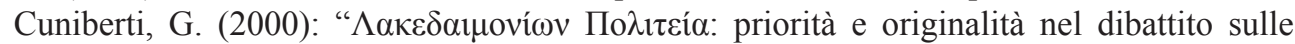
politeiai-modello di Sparta e Creta”, Studi Italiani di Filologia Classica 18.1, 99-111.

David, E.

(1982-83): “Aristotle and Sparta”, Ancient Society 13-14, 67-103.

(2007): "Xénophon et le mythe de Lycurgue", Ktèma 32, 297-310.

De Brasi, D. (2013): L'immagine di Sparta nei dialoghi platonici. Il guidizio di un filosofo su una (presunta) pólis modello (=International Plato Studies 33), Sankt Augustin.

De Laix, R. A. (1974): “Aristotle's Conception of the Spartan Constitution”, Journal of the History of Philosophy 12, 21-30 (http://dx.doi.org/10.1353/hph.2008.0694).

Díaz Tejera, A. (1975): “Análisis del libro VI de las Historias de Polibio respecto a la concepción cíclica de las constituciones", Habis 6, 23-34 (http://dx.doi.org/10.12795/ Habis.1975.i06.02).

Drews, R. (1979): "Phoenicians, Carthage and the Spartan Eunomia", American Journal of Philology 100.1, 45-58 (http://dx.doi.org/10.2307/294224).

Ducat, J.

(2016): "Platon, 'Petite histoire de la constitution spartiate', Lois III, 619d-692c", Ktèma 41, 331-341.

(2017): “Du caractère 'mixte' du régime spartiate”, Ktèma 42, 251-269.

Figueira, T. J. (2007): "Spartan 'Constitutions' and the Enduring Image of the Spartan Ethos", [en] Birgalias et alii (eds.), 2007, 143-158.

Fornis, C.

(2012): "La impronta de Esparta en el humanismo y la utopía del siglo XVI a.C.", Studia Historica. Historia Antigua 30, 333-345. 
(2015): "Bajo el signo de Licurgo: el reformismo atávico de Agis IV y Cleómenes III", Espacio Tiempo y Forma. Serie II, Historia Antigua 28, 19-37 (https://doi.org/10.5944/ etfii.28.2015.15124).

(2016): “La basileia 'revolucionaria' de Nabis", Sociedades Precapitalistas 5.2, s/p.

Fritz, K. von (1954): The Theory of the Mixed Constitution in Antiquity. A Critical Analysis of Polybius' Political Ideas, New York.

Futter, D. (2012): "Plutarch, Plato and Sparta", Akroterion 57, $35-51$ (https://doi. org/10.7445/57-0-130).

Gianotti, G. F. (2001): "Sparte, modèle historiographique de décadence", Cahiers $d u$ Centre Gustave-Glotz 12, 7-31 (https://doi.org/10.3406/ccgg.2001.1542).

Gräber, E. (1977): Die Lehre der Mischverfassung bei Polybios (=Schriften zur Rechtslehre und Politik 52), Bonn.

Gray, V. (1994): “Images of Sparta: Writer and Audience in Isocrates' Panathenaicus", [en] Powell - Hodkinson (eds.), 1994, 223-271.

Hansen, M. H. (ed.), (2005): The Imaginary Polis (=Acts of the Copenhagen Polis Centre 7; Historisk-filosofiske Meddelelser 91), Copenhagen.

Harding, P. (1973): “The Purpose of Isokrates'Archidamos and On the Peace", California Studies in Classical Antiquity 6, 137-149 (https://doi.org/10.2307/25010651).

Hermann-Otto, E. (1998): "Verfassung und Gesellschaft Spartas in der Kritik des Aristoteles", Historia 47/1, 18-40.

Herrmann, F. G. (2018): "Spartan Echoes in Plato's Republic", [en] Cartledge - Powell (eds.), 2018, 185-214 (https://doi.org/10.2307/j.ctv5jxmb3.12).

Hodkinson, S.

(1994): “'Blind Ploutos'?: Contemporary Images of the Role of Wealth in Classical Sparta", [en] Powell - Hodkinson (eds.), 1994, 183-222.

(2000): Property and Wealth in Classical Sparta, London (https://doi.org/10.2307/j. ctvvn96g).

(2005): “The Imaginary Spartan Politeia", [en] Hansen (ed.), 2005, 222-281.

Humble, N. (2018): "Sparta in Xenophon and Plato", [en] G. Danzig - G. Johnson D. Morrison (eds.), Plato and Xenophon. Comparative Studies (=Mnemosyne, Supplements 417), Leiden-Boston, 547-575 (https://doi. org/10.1163/9789004369085_022).

Keber, W. (1957): Platons Stellung zur Sparta-Ideologie, Diss. Westf. Univ. Münster.

Lévy, E.

(1987): “La Sparte de Polybe", Ktèma 12, 63-79.

(2001): "Le régime lacédémonien dans la Politique d'Aristote: une réflexion sur le pouvoir et l'ordre social chez les Grecs", [en] M. Molin (ed.), Images et représentations du pouvoir et de l'ordre social dans l'Antiquité (Actes du colloque d'Angers, 28-29 mai 1999), Paris, 57-72.

(2005): “La Sparte de Platon”, Ktèma 30, 217-236.

(2007): "Sosibios le Laconien", [en] D. Lenfant (ed.), Athénée et les fragments d'historiens, Actes du colloque de Strasbourg (16-18 juin 2005), Paris, 277-289.

Lupi, M. (2010): “Tibrone, Senefonte e le Lakedaimonion Politeiai del IV secolo (a proposito di Aristotele, Politica 1333B)", [en] M. Polito - C. Talamo (eds.), La Politica di Aristotele e la storiografia locale. Atti della Giornata di studio, Fisciano, 12-13 giugno 2008, Roma, 131-155.

Martínez-Lacy, R. (2005): “La Constitución mixta de Polibio como modelo político”, Studia Historica. Historia Antigua 23, 373-383. 
Morel, H. (1996): "Le régime mixte ou l'idéologie du meilleur régime politique", [en] M. Ganzin (ed.), L'influence de l'Antiquité sur la pensée politique européenne (XVI ${ }^{e}-X X^{e}$ siècles), (=Collection d'histoire des idées politiques 9), Aix-en-Provence, 95-112.

Morrow, G. R. (1960): Plato's Cretan City. A Historical Interpretation of the Laws, Princeton.

Nafissi, M. (1983-84): "La controversia sulla priorità fra le politeiai di Sparta e Creta: Eforo e Pausania", Annali della Facoltà di Lettere e Filosofia di Perugia 21, 343-366.

Ollier, F.

(1933): Le mirage spartiate. Étude sur l'idéalisation de Sparte dans l'antiquité grecque, I: De l'origine jusqu'aux cyniques, Paris.

(1943): Le mirage spartiate. Étude sur l'idéalisation de Sparte dans l'antiquité grecque, II: Du début de l'école cynique jusqu'à la fin de la cité, Paris.

Paradiso, A. (2000): "Lycurgue spartiate: analogie, anachronisme et achronie dans la construction historiographique du passé", [en] C. Darbo-Peschanski (dir.), Constructions du temps dans le monde grec ancien, Paris, 373-391.

Perlman, P. (2005): "Imagining Crete", [en] Hansen (ed.), 2005, 282-334.

Plácido, D. (1991): "Senofonte socratico", [en] L. Rossetti - O. Bellini (a.c.), Logos e Logoi, Napoli, 41-53.

Podes, S. (1991): "Polybius and his Theory of Anacyclosis: Problems of not Just Ancient Political Theory", History of Political Thought 12/4, 577-587.

Popper, K. R. (2006): La sociedad abierta y sus enemigos, Barcelona (1 $1^{\mathrm{a}}$ ed. 1945).

Powell, A. (1994): "Plato and Sparta: Modes of Rule and of Non-Rational Persuasion in the Laws", [en] Powell - Hodkinson (eds.), 1994, 273-321.

Powell, A. - Hodkinson, S. (eds.), (1994): The Shadow of Sparta, London-New York.

Rawson, E. (1969): The Spartan Tradition in European Thought, Oxford.

Richer, N. (2007): "Le modèle lacédémonien dans les oeuvres non historiques de Xénophon (Cyropédie exclue)", Ktèma 32, 405-434.

Sancho Rocher, L. (2008): "Democracia frente a populismo en Isócrates", Klio 90, 36-61 (https://doi.org/10.1524/klio.2008.0003).

Schofield, M. (2018): “Aristotle's Critique of Spartan Imperialism”, [en] Cartledge - Powell (eds.), 2018, 215-234 (https://doi.org/10.2307/j.ctv5jxmb3.13).

Schütrumpf, E. (1994): “Aristotle and Sparta”, [en] Powell - Hodkinson (eds.), 1994, 323345.

Thommen, L. (2000): “Spartas fehlende Lokalgeschichte”, Gymnasium 107, 399-408.

Tigerstedt, E. N.

(1965): The Legend of Sparta in Classical Antiquity, I, Stockholm.

(1974): The Legend of Sparta in Classical Antiquity, II, Stockholm.

Tober, D. (2010): "Politeiai and Spartan Local History", Historia 59/4, 412-431.

Walbank, F. W. (1966): "The Spartan Ancestral Constitution in Polybius", [en] E. Badian (ed.), Ancient Society and Institutions. Studies Presented to V. Ehrenberg, Oxford, 303312.

Wiater, N. (2018): “Getting Over Athens. Re-Writing Hellenicity in the Early Roman History of Dionysius of Halicarnassus", [en] M. Canevaro - B. Gray (eds.), The Hellenistic Reception of Classical Athenian Democracy and Political Thought, Oxford, 209-235 (https://doi.org/ 10.1093/oso/9780198748472.003.0010). 
